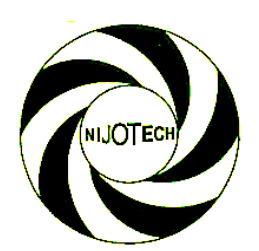

Nigerian Journal of Technology (NIJOTECH)

Vol. 39, No. 3, July 2020, pp. 710 - 720

Copyright@ Faculty of Engineering, University of Nigeria, Nsukka,

Print ISSN: 0331-8443, Electronic ISSN: 2467-8821

www.nijotech.com

http://dx.doi.org/10.4314/njt.v39i3.9

\title{
EFFECT OF NANOSILICA ON THE MECHANICAL AND MICROSTRUCTURAL PROPERTIES OF A NORMAL STRENGTH CONCRETE PRODUCED IN NIGERIA
}

\author{
I. M. Adamu1,*, J. M. Kaura², A. Lawan ${ }^{3}$ and A. Ocholi ${ }^{4}$

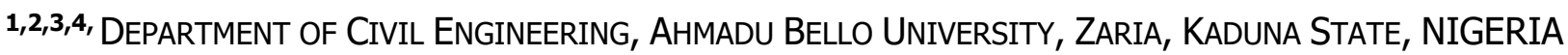 \\ Email addresses: 1 abrahimi1122@gmail.com, ${ }^{2}$ jmkaura@abu.edu.ng,3bnlawan@yahoo.co.uk, \\ 4 aocholi@abu.edu.ng
}

\begin{abstract}
The failure of conventional concrete to have classical mechanical properties, reduced permeability and lead to sustainability in concrete production called for the use of supplementary Cementitious Materials (SCM) in concrete to improve its performance. This study investigates the effect of adding optimal dosage of an SCM called nanosilica (nS) on the tensile and compressive strengths, microstructural properties and cement hydration reaction for grade 30 concrete. The optimal dosage of the $n S$ was determined to be $1.5 \%$ by weight of cement using compressive strength test. The influence of optimal ns dosage on the concrete properties was investigated using compressive strength test, splitting tensile strength test, Scanning Electron Microscopy (SEM) and Energy Dispersion Spectroscopy (EDS). Results revealed that optimal nS addition led to $30 \%$ and $23.3 \%$ respective increase in compressive and tensile strengths of conventional concrete at 7 days of curing. SEM micrographs show better packing density in the nano-concrete at 90days of curing. EDS shows that addition of optimal nS dosage in concrete led to formation of more C-S-H gels at 90days curing period, and a corresponding reduction in Ca/Si ratio of the nano-concrete to 0.89; a ratio that is very close to that of $14 \AA$ tobermorite reported in literature. The optimal nano-concrete can be used where strength improvement, especially at early age and reduction in concrete permeability are requirements.
\end{abstract}

Keywords: Compressive strength, Tensile strength, Normal strength nano-concrete, SEM, EDS.

\section{INTRODUCTION}

The world faces unprecedented global challenges related to depleting natural resources, pollution, climate change, clean water and poverty. These problems are directly linked to the physical characteristic of our current technology base for producing energy and materials products [1]. Concrete is one of the most common and predominantly used construction material in the construction of civil engineering infrastructure. It occupies nearly $70 \%$ of the volume of concrete structures and shows significant impact [2]. With morethan 11billion metric tons consumed each year, Portland cement concrete is the world's most widely used manufactured material, but it is also one of the most complex [3]. High global warming potential and poor durability performance in aggressive environment conditions are associated with Ordinary Portland cement (OPC) concrete production and usage [4]. According to [5] the appropriate use of mineral and chemical admixtures in concrete can improve its long-term strength and durability to aggressive conditions.

Cement is a basic constituent of concrete and is the largest manufactured product on earth [6]. The amount of $\mathrm{CO}_{2}$ emitted from the worldwide production of OPC corresponds to approximately $7 \%$ of the total emissions into the earth's atmosphere [7]. The emission of $\mathrm{CO}_{2}$ in cement and concrete industry can be controlled by incorporation of green concrete in the mix design, without reducing the quality of the final product [7]. According to [6] the major strategy

* Corresponding author, tel: +234-806-606-4858 
towards improving sustainable use of OPC is the use of mineral and chemical admixtures like ground granulated blast furnace slag (GGBS), pulverized fuel ash (PFA) and possibly nanosilica (nS) as Supplementary Cementitious Material (SCM). Up to $50 \%$ replacement of OPC with Ground Granulated Blast Furnace Slag (GGBS) have proven to improve mechanical and durability properties of concrete, while slowing the early age strength development [8].

In recent years, the use of $n S$ is receiving particular attention in the field of cement mortar and cement concrete. When ultra-fine particles are merged into Portland cement, mortar, and concrete, materials with different features from predictable materials could be obtained [9]. According to [10] recent studies on the use of $\mathrm{nS}$ in concrete helped to improve our understanding of the role of $\mathrm{nS}$ in cementitious materials matrix; this include cement hydration, mechanical properties and microstructure of concrete. Some of these effect are still not fully understood [10]. Ayad and Said [11] showed that the use of colloidal nS in cement mortar enhanced the compressive strength, reduces the total porosity and accelerates the pozzolanic reaction. The use of $n S$ in cement mortar was reported in [12], the study also showed that the addition of $\mathrm{nS}$ in cement mortar led to improvement in mechanical and microstructural properties of the mortar, moreover, the study reported that the improvement in strength and microstructural properties of the nS modified mortar was as a result of an increase in the quantity of Calcium Silicate Hydrate (C-S-H) gel in the nS modified mortar. In these studies, certain percentages of $n S$ were added to observe the effect on cement mortar strength development and microstructural properties improvement, but the optimal nS dosage was not determined.

Worldwide, resources are scarce and the demand for funds to be used for infrastructural development projects is always greater than supply, as a result, optimization in resource utilization in infrastructural development projects is gaining relevance across the globe. Moreover, optimal performance of hardened concrete is obtained by using optimal not the highest or lowest nS dosage. It is therefore necessary to determine the $\mathrm{nS}$ dosage that can guarantee optimal performance of hardened concrete so as to avoid wastage in material usage, which can result to unnecessary increase in the cost of concrete production without a corresponding improvement in the performance of the hardened concrete. [13] investigated the behavior of binary concrete containing $\mathrm{nS}$ and nanoferric (nF) oxide and observed that the addition of optimal dosage of $\mathrm{nS}$ determined to be $1.5 \%$ by weight of cement improved the strength and durability characteristics of the concrete. In another study conducted and reported in [14] for Polyethylene Terephthalate (PET) bottle waste nano-concrete, it was found that the addition of optimal nS dosage determined to be $3 \%$ by weight of cement improved the compressive, tensile and flexural strengths of the PET-nS concrete, the study also showed an improvement in microstructural properties of the PET-nS concrete caused by pore reduction in the interfacial transition zone between PET and cement in the concrete, resulting in dense microstructure. The improvement in mechanical and microstructural properties of the nano-concrete obtained in the studies presented was determined on a short-term curing period of 28days, whereas, a better understanding of the strength development characteristic and microstructural properties improvement of the nano-concrete could be achieved when a medium or long term concrete curing period is considered. Furthermore, different optimal dosage of nS were obtained in the studies presented, therefore, a need arise for determining the actual optimal dosage of $\mathrm{nS}$ in normal strength concrete; its effect on strength development, and microstructural properties improvement for a medium term curing period of at least 90days. Therefore, this study determined the mechanical and microstructural properties improvement of a normal strength nanoconcrete produced in Nigeria with optimal nS dosage, cured for a period of 90days, and provide the reasons for the improvements.

In Nigeria, concrete design are done according British Standards. The withdrawal of the recent versions of British Standards by British Standards Institution in Britain and their replacement with Eurocodes released by European Committee for standardization puts the fate of concrete design in Nigeria on Eurocodes. Therefore, this study generates nanoconcrete design data according to Eurocodes for use in civil engineering designs in Nigeria.

\section{MATERIALS AND METHODS}

\subsection{Material}

Portland Limestone Cement type II B-L produced according to Nigerian Industrial Standard (NIS444$1: 2003)$ by Cement Company of Northern Nigeria was 
used in all mixes. The nS used has a commercial name VK-SP15. Glenium based Hydroplast 500 produced by Armosil Itd was used as superplastisizer. Sharp sand finer than $4.5 \mathrm{~mm}$ sieve and crushed aggregate of $25 \mathrm{~mm}$ maximum size obtained from local suppliers were used for all the concrete mixes. The fine aggregate has specific gravity (SSD), finess modulus, moisture content (SSD), absorption capacity and dry rodded unit weight of 2.67, 2.60, $3 \%, 2 \%$ and $1550 \mathrm{~kg} / \mathrm{m}^{3}$ respectively. The coarse aggregate has specific gravity (SSD), moisture content (SSD), absorption capacity, flakiness, elongation, impact value and crushing value of 2.5 , $0.90 \%, 0.89 \%, 20.4 \%, 30.2 \%, 17.4 \%$ and $27.9 \%$ respectively. The grading of the coarse and fine aggregates used conformed to the requirements of ASTM C33/C33M (2018), BS EN933-1:2012 and BS EN12620:2002. Clean water conforming to the requirements of BS EN1008:2002 was used in concrete sample production.

\subsection{Concrete Mix Design and Validation}

Grade 30 control mix was designed according to American Concrete Institute (ACI 211.1-98: 2004) method for normal concrete mixes with target mean cylindrical compressive strength of $31.87 \mathrm{~N} / \mathrm{mm}^{2}$ derived from the target cube compressive strength of $39.4 \mathrm{~N} / \mathrm{mm}^{2}$ at 28 days. The target slump value was $80 \mathrm{~mm}$ using $25 \mathrm{~mm}$ maximum aggregate size. The design was implemented using MS Excel (2007). The mix proportions obtained was used to produce laboratory trial mixes for slump and compressive strength tests according to BS EN206:2013. The fresh concrete was tested for slump in accordance with BS EN12350-2:2009. The concrete samples produced according to BS EN206:2013 were subjected to compressive strength test at 28days of curing in line with the provisions of BS EN12390-3:2009. Laboratory adjustments were made to the trial mixes to meet characteristic cube compressive strength and design slump values. The characteristic cube strength of the control mix was obtained using equation (1) utilizing the measures of dispersion (mean, standard deviation and coefficient of variation) obtained after statistical analysis of experimental data using MS Excel (2007). The trial and validated mix proportions are presented in Table 1 . The validated mix containing varying proportions of $\mathrm{nS}$ is presented in Table 2.

$\mathrm{f}_{\mathrm{cu}}=\mathrm{f}_{\mathrm{m}}-1.64 \mathrm{~S}_{d}$

Where: $f_{c u}$ is characteristic strength, $f_{m}$ is mean strength, $\mathrm{S}_{d}$ is standard deviation.

Table 1: Trial and validated mix proportions

\begin{tabular}{|c|c|c|c|c|c|c|c|c|}
\hline \multirow[t]{2}{*}{ Mix Type } & \multirow[t]{2}{*}{ Grade } & \multirow[t]{2}{*}{ W/C } & \multirow{2}{*}{$\begin{array}{c}\text { Cement } \\
\mathrm{kg} / \mathrm{m}^{3}\end{array}$} & \multicolumn{2}{|c|}{ Aggregates } & \multirow{2}{*}{$\begin{array}{l}\text { Water } \\
\mathrm{kg} / \mathrm{m}^{3}\end{array}$} & \multicolumn{2}{|c|}{ Superplastisizer } \\
\hline & & & & $\begin{array}{l}\text { Coarse } \\
\mathrm{kg} / \mathrm{m}^{3}\end{array}$ & $\begin{array}{c}\text { Fine } \\
\mathrm{kg} / \mathrm{m}^{3}\end{array}$ & & $\%$ & $\begin{array}{l}\text { Weight } \\
\mathrm{kg} / \mathrm{m}^{3}\end{array}$ \\
\hline $\begin{array}{l}\text { Design (Trial } \\
\text { Mix) }\end{array}$ & 30 & 0.50 & 390 & 963 & 835 & 163 & 2.00 & 7.80 \\
\hline Validated Mix & 30 & 0.45 & 433 & 963 & 797 & 165 & 2.00 & 8.66 \\
\hline
\end{tabular}

Table 2: Validated mix containing varied proportions of nano-silica

\begin{tabular}{|c|c|c|c|c|c|c|c|c|c|c|}
\hline \multirow[t]{3}{*}{ Grade } & \multirow[t]{3}{*}{ Designation. } & \multirow[t]{3}{*}{ W/C } & \multirow{3}{*}{$\begin{array}{l}\text { Cement } \\
\mathrm{kg} / \mathrm{m}^{3}\end{array}$} & \multicolumn{2}{|c|}{ Nanosilica } & \multirow{2}{*}{\multicolumn{2}{|c|}{$\begin{array}{l}\text { Aggregate } \\
\mathrm{kg} / \mathrm{m}^{3}\end{array}$}} & \multirow{3}{*}{$\begin{array}{l}\text { Water } \\
\mathrm{kg} / \mathrm{m}^{3}\end{array}$} & \multicolumn{2}{|c|}{ Superplastisizer } \\
\hline & & & & \multirow[t]{2}{*}{$\%$} & \multirow[t]{2}{*}{$\mathrm{kg} / \mathrm{m}^{3}$} & & & & $\%$ & $\mathrm{~kg} / \mathrm{m}^{3}$ \\
\hline & & & & & & Fine & Coarse & & & \\
\hline \multirow{7}{*}{30} & NSO & & 433 & 0.0 & 0.0 & \multirow{7}{*}{797} & \multirow{7}{*}{963} & \multirow{7}{*}{165} & \multirow{7}{*}{2.00} & \multirow{7}{*}{8.70} \\
\hline & NS0.5 & & 431 & 0.5 & 2.2 & & & & & \\
\hline & NS1 & & 429 & 1.0 & 4.3 & & & & & \\
\hline & NS1.5 & 0.45 & 427 & 1.5 & 6.5 & & & & & \\
\hline & NS2 & & 425 & 2.0 & 8.7 & & & & & \\
\hline & NS2.5 & & 423 & 2.5 & 10.8 & & & & & \\
\hline & NS3 & & 420 & 3.0 & 13.0 & & & & & \\
\hline \multirow{2}{*}{30} & 30NSO & \multirow{2}{*}{0.45} & 433 & 0.0 & 0.0 & \multirow{2}{*}{797} & \multirow{2}{*}{963} & \multirow{2}{*}{165} & \multirow{2}{*}{2.00} & \multirow{2}{*}{8.66} \\
\hline & 30NS1.5 & & 427 & 1.5 & 6.5 & & & & & \\
\hline
\end{tabular}




\subsection{Preparation of Concrete Samples}

The process of preparation and casting of test samples for determination of optimal nano-silica dosage, determination of tensile and compressive strength development of the nano-concrete is presented in this section. NS1.5 stands for nanoconcrete having $1.5 \%$ nano-silica dosage, while NSO is the control concrete mix for determination of optimal nano-silica dosage. 30NSO and 30NS1.5 stand for grade 30 control concrete mix and nanoconcrete mix having $1.5 \%$ nano-silica dosage by weight of cement respectively for determining strength development characteristics of the nanoconcrete. The work was conducted at Concrete Laboratory, Civil Engineering Department, Ahmadu Bello University, Zaria, Nigeria. The test samples were prepared according to BS EN12390-1:2012 and BS EN12390-2:2009.

\subsubsection{Determination of Optimal Nano-Silica Dosage}

The weight of cement from laboratory validated mix proportions for control concrete was recorded. To determine the optimal nanosilica dosage, cement replacement by nano-silica of $0.5 \%$ to $3.0 \%$ at interval of $0.5 \%$ by weight of cement was used. A mix was produced for the control samples without nano-silica and with the varying percentages of nano-silica for determination of optimal nano-silica dosage. Hydroplast 500 superplastisizer having $2 \%$ content by weight of cement was added to both the control and nano-concrete mixes. The control mix; having zero percentage of nano-silica was produced by mixing cement and aggregate (coarse and fine aggregate) individually in the mixer. A homogeneous concrete mix was obtained with all the constituents mixed together with addition of potable water and superplastisizer; mixed uniformly with the constituents to enhance workability. Due to high surface area of the nano-silica and the difficulty associated with its dispersal, the mixing was done by stirring nano-silica with water and superplastisizer at a high speed for 5 minutes using Altrad Minimix 130 Concrete Mixer. The cement was added to the mixer and mixed at medium speed, fine aggregate was then gradually added followed by coarse aggregate. The concrete mix was placed in $100 \mathrm{~mm} \times 100 \mathrm{~mm}$ $x 100 \mathrm{~mm}$ oiled moulds and vibrated on a vibrating table. Demoulding of the test specimens was done after 24 hours of casting. The specimens were cured for a period of 7 and 28days in water tanks under laboratory conditions. Slump test was conducted according to BS EN12350-2:2009 to assess the workability of concrete mixes.

\subsubsection{Determination of Compressive and Tensile Strength Development}

The weight of cement from validated mix proportions for the control concrete was used. The optimal nano-silica dosage determined to be $1.5 \%$ by weight of cement was added to produce nanoconcrete samples. The corresponding control concrete samples for tensile and compressive strength test were produced. The sample size, mixing and demoulding procedure for the compressive strength development investigation was as used for determining optimal nano-silica dosage. The samples produced for determining splitting tensile strength were cylindrical having $150 \mathrm{~mm}$ diameter and $300 \mathrm{~mm}$ height. The mixing procedure for the concrete samples was as outlined above. The specimens were cured for a period of 3 , $7,14,21,28,42,56,70$ and 90 days in water tanks under laboratory conditions. Three samples were produced for each curing age and strength test type.

\subsection{Strength Tests}

The strength test done was divided into compressive strength test and splitting tensile strength test. The tests were conducted to determine the optimal nano-silica dosage, compressive and tensile strength development characteristic of the nano-concrete mixes. The detailed test procedure for the two strength tests are presented below.

\subsubsection{Compressive Strength Test}

The compressive strength test for determining optimal nS dosage was conducted at 7 and 28days of curing according to BS EN12390-3:2009. In order determine the strength development characteristics of the nano-concrete mixes in comparison to the control concrete mixes, the compressive strength test was conducted at 3, 7, 14, 21, 28, 42, 56, 70 and 90days of curing. The tests were conducted on Avery Denison Universal Testing Machine. The load rate was kept at $0.6 \pm 0.2 \mathrm{MPa} / \mathrm{Sec}$ according to $\mathrm{BS}$ EN12390-3:2009 for all test samples until the specimen failed. The failure loads were recorded. The compressive strength was calculated by dividing the failure load by cross-sectional area of the cube 
sample. The mean strength was obtained by taking average of the compressive strength of three concrete cube samples in accordance with BS EN12390-3:2009. The characteristic strength of the control mix was obtained using equation (1) utilizing the measures of dispersion (mean, standard deviation and coefficient of variation) obtained after statistical analysis of experimental data using MS Excel (2007).

To allow for concrete design according to EN19921-1(2004), the characteristic cube strength obtained were converted to characteristic cylindrical strength using equation (2) from [15].

$\mathrm{f}_{\text {cyl }}=0.85 \mathrm{f}_{\text {cu }}-1.6$

Where: $f_{\text {cyl }}$ is characteristic cylindrical strength, $f_{\text {cube }}$ is characteristic cube strength of test specimens respectively.

\subsubsection{Splitting Tensile Strength Test}

The splitting tensile strength test was conducted according to BS EN12390-6:2009 after 3, 7, 14, 21, $28,42,56,70$ and 90 days of curing. The test was conducted on Avery Denison Universal Testing Machine. The load rate was kept at 0.04 to $0.06 \mathrm{MPa} / \mathrm{Sec}$ according to BS EN12390-6:2009 for all test samples until the specimen failed. The failure loads were recorded. The splitting tensile strength was calculated using equation (3) according to EN12390-6:2009.

$$
\mathrm{f}_{\mathrm{st}}=\frac{2 \mathrm{P}_{\mathrm{s}}}{\pi L D}
$$

Where: $f_{s t}$ is splitting tensile strength, $P_{s}$ is failure load, $L$ and $D$ are length and diameter of the cylindrical specimen respectively.

For design purpose, the splitting tensile strength results were converted to axial tensile strength using equation (4) according to EN1992-1-1 (2004).

$$
\mathrm{f}_{\mathrm{ct}}=0.9 \mathrm{f}_{\mathrm{st}}
$$

Where: $f_{c t}$ is axial tensile strength, and $f_{s t}$ is splitting tensile strength.

\subsection{SEM and EDS Analysis for Concrete Samples}

The surface morphology of the nano-concrete test samples containing optimal nano-silica dosage and the corresponding control samples without nanosilica at 28 and 90days of curing was determined using Scanning Electron Microscope (SEM). The rate of formation of C-S-H gel in the nano and control concrete was investigated using Energy Dispersion Spectroscopy (EDS) at 90days of curing. Samples not more than $10 \mathrm{~mm}$ in size were collected from test samples after compressive strength test at the specified age for EDS and SEM analysis. The SEM and EDS analysis were done using Phenom ProX SEM machine. The collected samples were prepared and placed on the sample holder of the SEM machine. Thereafter, the samples were illuminated with X-ray beam of $15 \mathrm{kV}$ magnitude. The proportion of the energy emitted which is unique to the morphology and chemistry of the samples was analyzed for the morphology, elemental composition, and percentage of the elements in the samples.

\section{RESULTS AND DISCUSSION}

\subsection{Properties of Trial and Validated Concrete Mixes}

The strength properties; mean compressive strength and characteristic strength, as well as slump values obtained when the trial and validated concrete control mixes were implemented in the laboratory are presented in Table 3. The trial mix characteristic cube compressive strength (fcu) obtained was $23.71 \%$ short of the desired characteristic cube strength for the grade 30 control concrete mix. The slump value obtained was $93.75 \%$ more than the design slump. The excess slump value obtained was as a result of superplastizer addition which was designed taking into account the workability reduction effect of nano-silica as observed in the preliminary concrete mixes. The failure of the designed concrete to meet the strength requirements of grade 30 concrete reinforces the assertion by [16] that concrete mix design calculations provide an intelligent guess, not the exact mix proportions for a given concrete grade. Exact mix proportions are obtained from laboratory trial mixes and adjustments.

For the validated mix properties of the control concrete grade presented in Table 3 , the characteristic cube compressive strength (fcu) obtained was $1.47 \%$ more than the desired characteristic cube strength for grade 30 concrete, which is adequate. The slump value obtained was $68.75 \%$ more than the design slump, but is within acceptable limits, especially for production of nanoconcrete, whose $\mathrm{nS}$ finess reduces workability. This proved the assertion by [16]; that exact concrete mix proportions are obtained from laboratory trial mixes and adjustments. 


\subsection{Optimal Dosage of Nano-Silica in Grade 30 Concrete}

There was an increase in compressive strength on addition of $0.5 \%$ to $1.5 \%$ (NS0.5 to NS1.5) nS by weight of cement at both 7 and 28days of curing as shown in Figure 1. Thereafter, a drop in compressive strength was observed up to $3 \% \mathrm{nS}$ addition (NS2 to NS3) at 7 and 28days of curing. The highest and lowest compressive strengths of the nano-concrete mixes were $27.3 \mathrm{~N} / \mathrm{mm}^{2}$ and $19.6 \mathrm{~N} / \mathrm{mm}^{2}$ at 7days, and $37 \mathrm{~N} / \mathrm{mm}^{2}$ and $27.67 \mathrm{~N} / \mathrm{mm}^{2}$ at 28days respectively. The maximum gain in compressive strength of the nano-concrete was recorded on mix NS1.5 having $1.5 \%$ nS dosage at both 7 and 28days of curing. This means that optimal compressive strength gain was recorded on nano-concrete cubes with NS1.5 designation having $1.5 \%$ nano-silica dosage, signifying that the optimal nS dosage in grade 30 concrete mix is $1.5 \%$ by weight of cement, as concluded by [17].

\subsection{Compressive Strength Development of Grade 30 Nano-Concrete Mix}

The highest and lowest compressive strength values obtained for the optimal nano-concrete mix (30NS1.5) were $41 \mathrm{~N} / \mathrm{mm}^{2}$ and $20 \mathrm{~N} / \mathrm{mm}^{2}$ at 90 and 3days of curing respectively, as shown in figure 2 . The mix containing optimal nano-silica dosage (30NS1.5) showed higher compressive strength than control concrete mix (30NSO) at all curing ages. There was $11.11 \%, 30 \%, 17.41 \%, 11.24 \%$, $14.55 \%, 8.65 \%, 12.04 \%, 8.53 \%$ and $8.75 \%$ increase in compressive strength of the nanoconcrete mix at 3, 7, 14, 21, 28, 42, 56, 70 and 90days respectively in comparison with the conventional concrete mix. This shows that nanoconcrete has higher compressive strength than conventional concrete of the same grade. Furthermore, the improvement in compressive strength of the optimal nano-concrete mix (30NS1.5) was more pronounced at 7days of curing than at the other curing ages, as concluded by [14] and [17]; whose study considered curing period of 3 to 28 days. The early age compressive strength gain of nano-concrete mix might be due to accelerated hydration reaction on addition of optimal dosage of nano-silica.

There was $85 \%$ increase in compressive strength of nano-concrete mix between 3 and 28 days of curing, whereas $10.81 \%$ compressive strength gain was recorded between 28 and 90 days of curing. This shows that the most significant increase in compressive strength of the nano-concrete mix was between 3 and 28 days of curing, which is in line with the conclusions of [12], [14] and [17] whose study considered a curing period of 3 to 28 days. This pattern of strength development in the optimal nano-concrete mix could be attributed to accelerated hydration of the mix leading to early consumption of portlandite and lime in the presence of nS.

The results show that the highest percentage of hydration for the optimal nano-concrete mix was complete at 28 days; the remaining negligible hydration was very slow up to 90 days of curing. Therefore, it could be concluded that the accelerated compressive strength gain of the nano-concrete mix at early age is an indication that nano-silica does not only serve as filler to increase the density of the micro and nano structure of concrete, but also work as an activator in the process of hydration.

\subsection{Tensile Strength Development of Grade $\mathbf{3 0}$ Nano-Concrete Mix}

The respective lowest and highest values of splitting tensile strength of the optimal nano-concrete mix (30NS1.5) were $2.13 \mathrm{~N} / \mathrm{mm}^{2}$ and $4.15 \mathrm{~N} / \mathrm{mm}^{2}$ at 3 and 90 days of curing, as presented in figure 3 . The splitting tensile strength of the optimal nanoconcrete mix (30NS1.5) at 3, 7, 14, 21, 28, 42, 56, 70 and 90 days was improved by $7.04 \%, 23.3 \%$, $16.47 \%, 19.19 \%, 13.47 \%, 7.71 \%, 8.58 \%, 8.12 \%$ and $8.64 \%$ respectively in comparison with the control concrete mix (30NS0). This shows that nanoconcrete has higher tensile strength than an equivalent conventional concrete. Moreover, the improvement in splitting tensile strength of the nano-concrete mix was more pronounced at 7 days of curing than at the other curing ages as concluded by [14]. The early age splitting tensile strength gain of the nano-concrete mix might be due to accelerated hydration reaction on addition of optimal dosage of $\mathrm{nS}$.

There was $85.92 \%$ increase in splitting tensile strength of nano-concrete mix between 3 and 28 days of curing, whereas $4.80 \%$ splitting tensile strength gain was recorded between 28 and 90 days of curing. This shows that the most significant increase in splitting tensile strength of the nanoconcrete mix was between 3 and 28 days of curing, in line with the conclusions of [14]. This could be due to accelerated hydration of the nano-concrete mix, leading to the formation of more C-S-H gels. 
The results show that maximum percentage of hydration of the nano-concrete mix was complete at 28 days; the remaining negligible hydration was very slow up to 90days of curing. The increase in tensile strength of the nano-concrete mix might be due to improved properties of the concrete mix and the strong inter-phase bond between the binders (cement and $\mathrm{nS}$ ) and the aggregates used. The tensile strength gain in nano-concrete mix could also be as a result of improvement in the interfacial transition zone bonding of the concrete.

\subsection{Compressive and Tensile Strengths of Concrete according to EN1992-1-1(2004)}

To allow for nano-concrete design according to EN1992-1-1 (2004) and its reference standards, and also for the purpose of strength comparison with the control concrete, the calculated characteristic compressive and tensile strengths of the control (30NSO) and optimal nano-concrete (30NS1.5) mixes at 28days reference curing period according to the European standard are presented in Table 4. The splitting tensile strength values obtained at the reference curing period were converted to axial tensile strength, while the characteristic cube compressive strengths were converted to cylindrical characteristic strength. The conversion of cube compressive strength to cylindrical strength, as well as splitting tensile strength to axial tensile strength led to reduction in compressive and tensile strengths for all the concrete mixes. There was $17.36 \%$ and $13.38 \%$ increase in characteristic cylindrical compressive strength and axial tensile strength on additional of optimal nS dosage in grade 30 concrete.

Table 3: Properties of Trial and Validated Concrete Mixes

\begin{tabular}{|c|c|c|c|c|c|c|c|}
\hline \multirow[b]{2}{*}{ Concrete Mix Type } & \multirow[b]{2}{*}{$\begin{array}{l}\text { Concrete } \\
\text { Grade }\end{array}$} & \multicolumn{2}{|c|}{ Strength Parameters } & \multicolumn{2}{|l|}{ Slump } & \multicolumn{2}{|c|}{ Statistics } \\
\hline & & $\begin{array}{l}\mathrm{Fcu} \\
\mathrm{N} / \mathrm{mm}^{2}\end{array}$ & $\begin{array}{l}\mathrm{Fm} \\
\mathrm{N} / \mathrm{mm}^{2}\end{array}$ & $\begin{array}{l}\text { Design } \\
\mathrm{mm}\end{array}$ & $\begin{array}{l}\text { Achieved } \\
\mathrm{mm}\end{array}$ & SD & $\mathrm{COV}$ \\
\hline Design Mix (Trial Mix) & 30 & 24.25 & 27.67 & 80 & 155 & 2.08 & 0.08 \\
\hline Validated Mix & 30 & 30.44 & 32.33 & 80 & 135 & 1.16 & 0.04 \\
\hline
\end{tabular}

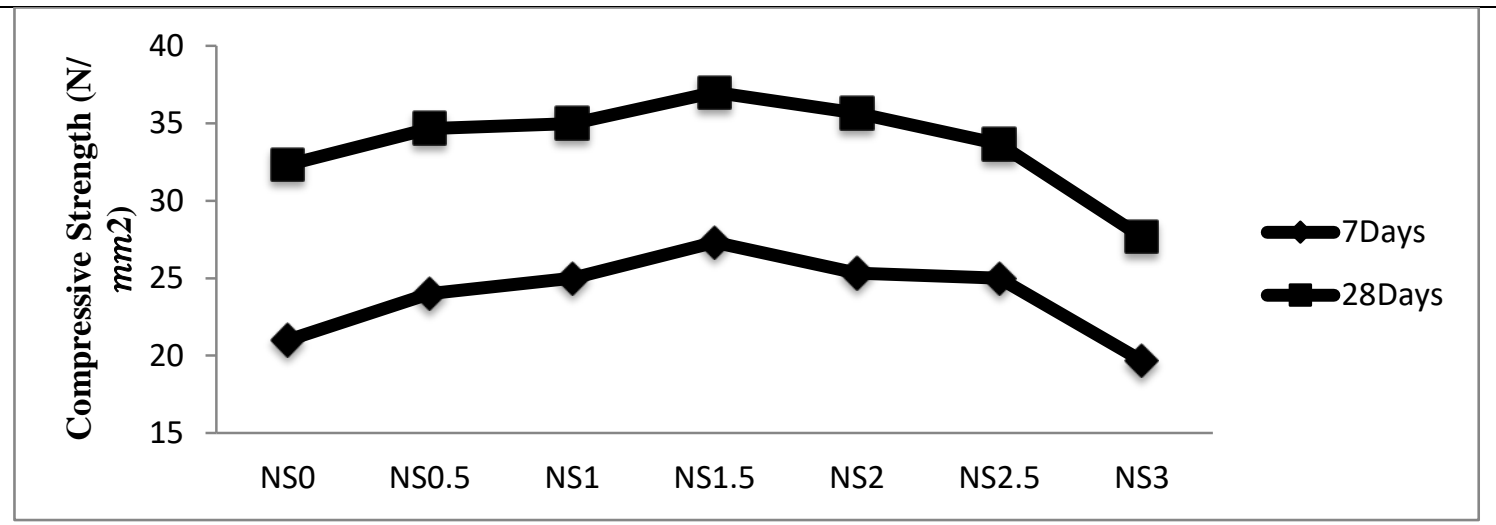

Figure 1: Compressive Strength of Grade 30 Mixes at 7 and 28days of Curing

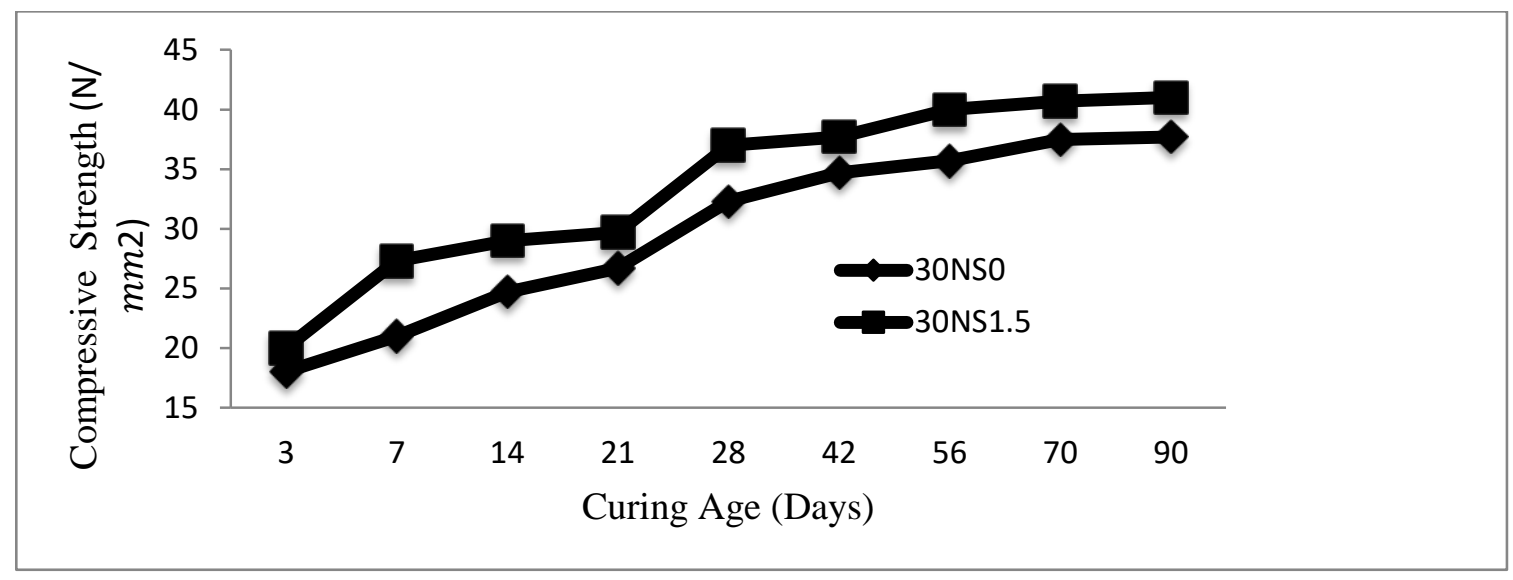

Figure 2: Compressive Strength Development of Grade 30 Control and Nano-Concrete Mixes 


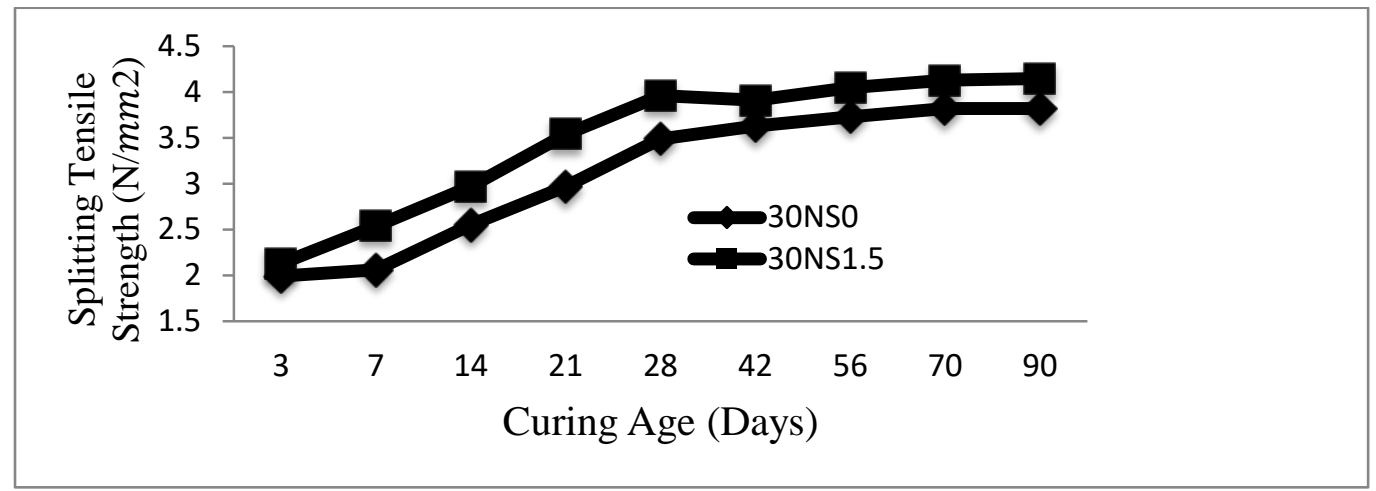

Figure 3: Tensile Strength Development of Grade 30 Control and Nano-Concrete Mixes

Table 4: Concrete Characteristic Strength Parameters according to EN1992-1-1 (2004)

\begin{tabular}{ccccc}
\hline & \multicolumn{2}{c}{ Strength Parameters } & \multicolumn{2}{c}{ Strength Parameters (EN1992-1-1(2004) } \\
\cline { 2 - 5 } Concrete Mixes & $\begin{array}{c}\text { Compressive } \\
\text { Cube }\end{array}$ & $\begin{array}{c}\text { Splitting Tensile } \\
\text { Cylindrical }\end{array}$ & $\begin{array}{c}\text { Compressive } \\
\text { Cylindrical }\end{array}$ & $\begin{array}{c}\text { Axial Tensile } \\
\text { Cylindrical }\end{array}$ \\
& $\mathrm{f}_{\mathrm{cu}}$ & $\mathrm{f}_{\mathrm{st}}$ & $\mathrm{f}$ & $\mathrm{f}_{\text {cyl }}$ \\
$\mathrm{N} / \mathrm{mm}^{2}$ & $\mathrm{~N} / \mathrm{mm}^{2}$ & 24.2 & $\mathrm{~N} / \mathrm{mm}^{2}$ \\
\hline 30NS0 & 30.4 & 3.49 & 28.4 & 3.14 \\
30NS1.5 & 35.3 & 3.96 & & 3.56 \\
\hline
\end{tabular}

\subsection{Relationship between Nano-Concrete Strength Properties and Microstructure}

SEM examination was performed on control and nanoconcrete samples at 28 and 90days of curing to allow for verification of the mechanism predicted by compressive and splitting tensile strength tests. The SEM images of the control concrete mix at 28 and 90days curing period are presented in Figure 4(a) and (c) respectively. The corresponding SEM images for the optimal nano-concrete mix at 28 and 90days curing period are presented in Figure $4(\mathrm{~b})$ and (d) respectively. A dense and compact formation of hydration products was observed for the nanoconcrete at 90days of curing unlike porous plate like structure of the control concrete at the same curing age. Moreover, a dense interfacial layer between aggregates and cement paste was observed for the nano-concrete at 90days of curing. The crack which appear on the surface of the nano-concrete SEM image at 90days of curing could be attributed to the load applied to the cube to obtain the $10 \mathrm{~mm}$ fractured size sample for the analysis. Furthermore, the improvement in the packing density of the normal strength nano-concrete was more pronounced at 90days of curing (Figure 4(d)) than at 28days of curing (Figure 4(b)). Therefore, it could be said that the microstructural properties of a normal strength nano- concrete could be better assessed at 90days of curing than at 28days reference curing period.

The high quantity of C-S-H gel formed in the nanoconcrete was confirmed, as high content of calcium (Ca) and Silica $\left(\mathrm{SiO}_{2}\right)$ was found in the EDS spectrum of the nano-concrete, as presented in Figure 5. Thus, it could be concluded that the improvement in the tensile and compressive strengths of the nanoconcrete was as a result of densification and pore refinement.

\subsection{Relationship between Nano-Concrete Strength Properties and $\mathrm{Ca} / \mathrm{Si}$ ratio}

In order to provide a correlation between compressive and tensile strengths development of nano-concrete and $\mathrm{Ca} / \mathrm{Si}$ ratio, the weight concentrations of the two elements in both the control and optimal nanoconcrete mix was determined using EDS. The optimal nano-concrete mix (30NS1.5), which has higher compressive and tensile strengths, has lower $\mathrm{Ca} / \mathrm{Si}$ ratio than the control concrete mix (30NSO) at 90days of curing, as shown in Table 5 . The $\mathrm{Ca} / \mathrm{Si}$ ratio of the nano-concrete was calculated as 0.89 from weight concentration of the two elements which is very close to 0.81 ; the $\mathrm{Ca} / \mathrm{Si}$ ratio of $14 \hat{\AA}$ tobermorite $\mathrm{C}-\mathrm{S}-\mathrm{H}$ model reported in [18]. This shows that the compressive and tensile strengths of nano-concrete increase with decrease in $\mathrm{Ca} / \mathrm{Si}$ ratio. 


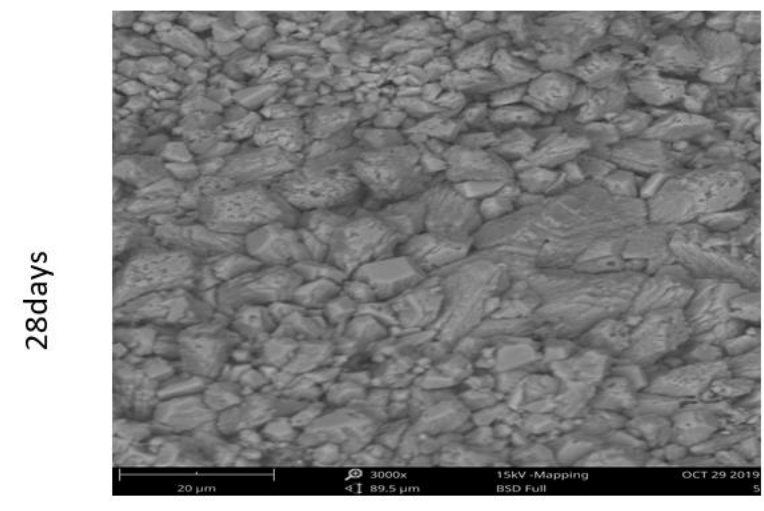

(a)

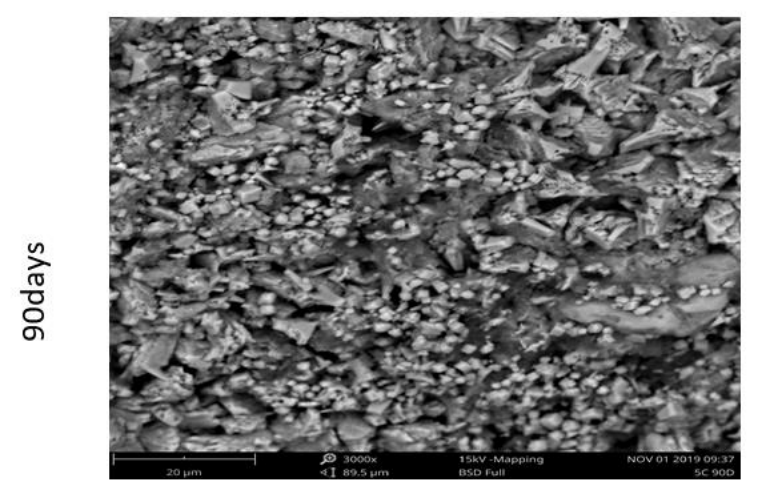

(c)

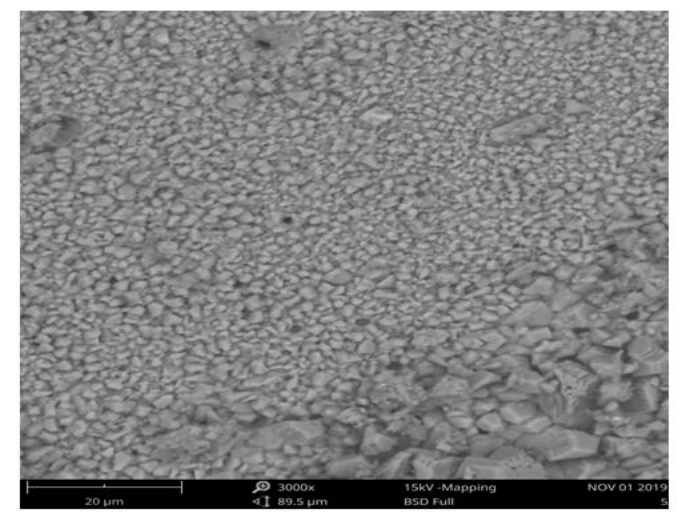

(b)

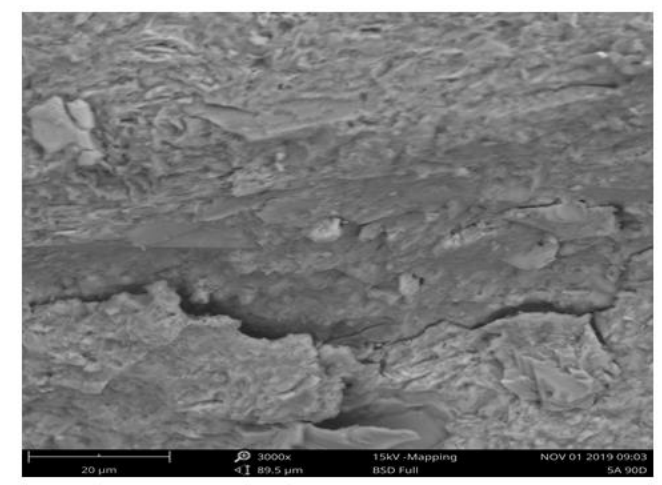

(d)

Figure 4: SEM images of concrete at 28 and 90days of curing. (a) control concrete at 28days, (b) nanoconcrete at 28days, (c) control concrete at 90days, (d) nano-concrete at 90days.

Table 5: Ca/Si ratios of the grade 30 concrete at godays of curing

\begin{tabular}{llll}
\hline $\begin{array}{l}\text { Concrete } \\
\text { Mix }\end{array}$ & Element & $\begin{array}{l}\text { Weight } \\
\text { Concentration (\%) }\end{array}$ & $\begin{array}{l}\text { Ca/Si } \\
\text { ratio }\end{array}$ \\
\hline \multirow{3}{*}{30 NSO } & $\begin{array}{l}\text { Calcium } \\
\text { (Ca) }\end{array}$ & 37.05 & 1.90 \\
& Silicon (Si) & 19.50 & \\
\hline \multirow{3}{*}{30 NS1.5 } & $\begin{array}{l}\text { Calcium } \\
\text { (Ca) }\end{array}$ & 34.31 & 0.89 \\
& Silicon (Si) & 38.55 & \\
\hline
\end{tabular}

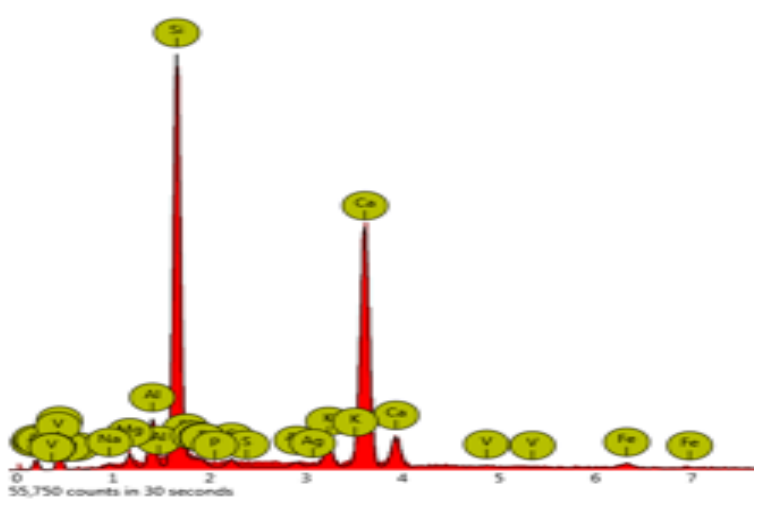

Figure 5: EDS spectrum of nano-concrete at 90 days of curing
Furthermore, it could be said that the addition of optimal nS in concrete makes its internal structure and bond assembly to approach that of $14 \hat{\AA}$ tobermorite reported in literature.

\section{CONCLUSION}

The effect of optimal $\mathrm{nS}$ dosage on strength and microstructural properties of a normal strength concrete reported in this study showed that addition of optimal nS dosage improves the strength and microstructural properties of concrete. From the results, the following conclusions were drawn:

1. The optimal nS dosage in grade 30 normal strength concrete was determined to be $1.5 \%$ by weight of cement.

2. The addition of optimal nS dosage in normal strength concrete led to improvement in compressive and tensile strengths of nanoconcrete mixes with increase in curing age. The addition of optimal nS led to $30 \%$ and $23.3 \%$ respective increase in compressive and tensile strengths of conventional concrete at 7days of curing. 
3. The most significant improvement in the tensile and compressive strengths of normal strength nano-concrete was between 3 and 28days of curing, whereas, a negligible increase in compressive and tensile strengths of the nanoconcrete exist between 28 and 90days of curing. Therefore, the practice of using 28days reference curing period to determine characteristic strength in concrete is actually a good one and could be extended to normal strength nano-concrete.

4. The use of optimal nS in normal strength concrete could overcome the shortcomings in early age strength development of Ground Granulated Blast Furnace Slag (GGBS) in the production of high strength concrete.

5. Addition of optimal dosage of $\mathrm{nS}$ in normal strength concrete mixes improved the microstructural properties of the matured concrete at 28 and 90days of curing through densification and pore refinement, thereby reducing permeability and void content.

6. The effect of optimal $n S$ dosage on the packing density of normal strength nano-concrete was more pronounced at 90days of curing than at 28days curing period. Therefore, the microstructural properties of a normal strength nano-concrete could be better assessed at 90 days of curing.

7. Optimal nS addition in normal strength nanoconcrete reduced $\mathrm{Ca} / \mathrm{Si}$ ratio at 90 days of curing to 0.89 , a value very close 0.81 ; the $\mathrm{Ca} / \mathrm{Si}$ ratio of $14 \hat{A}$ tobermorite C-S-H model reported in literature, thereby, resulting in improved hydration reaction and corresponding increase in tensile and compressive strengths of the normal strength nano-concrete.

8. Addition of optimal nS dosage in grade 30 normal strength concrete led to $17.36 \%$ and $13.38 \%$ respective increase in characteristic cylindrical compressive and axial tensile strengths determined according to Eurocodes.

\section{REFERENCES}

[1] Drexler, E., and Pamlin, D. "Nano-Solutions for the Twenty-First Century: Unleashing the Fourth Technology Revolution". Low Carbon Leaders, 2013.

[2] Venkat Rao, N., Rajasekhar, M., Vijayalakshmi, K. and Vamshykrishna, M. "The Future of Civil Engineering with the Influence and Impact of Nanotechnology on Properties of Materials", 2nd International Conference on Nanomaterials and Technologies (CNT 2014), Procedia Material Science, ScienceDirect, Vol. 10, Number 1, 2015, pp 111-115.

[3] Allen, J. A., Thomas, J. J., and Jennings, H. M. "Composition and Density of nanoscale Calcium-Silicate-Hydrate in Cement", Nature Materials, Vol. 6, Number 2, 2007, pp.:311-316.

[4] Duxson, P., Provis, J. L., Lukey, G. C., and Van Deventer, J. S. "The Role of Inorganic Polymer Technology in the Development of 'green Concrete". Cement and Concrete Research, Vol. 37, Number 2, 2007, pp: 1590-1597.

[5] Thomas, M. "Supplementary Cementing Materials in Concrete", Taylor and Francis, United States of America, 2013.

[6] Scrivener, K., John, V., and Gartner, E "EcoEfficient Cements: Potential, Economically Viable Solutions for a Low CO2, Cement Based Materials Industry". United Nations Environment Program, Paris, France, 2016.

[7] Mistry, J., Patel, I., and Shah, J. "Study on Effect of Nano Materials on Various Properties of Concrete", Journal of Civil Engineering and Environmental Technology, Vol. 1, Number 4, 2014, pp: 36-39.

[8] Claisse, P., A. "Civil Engineering Materials", Butterworth-Heinemann, Elsevier, Oxford, United Kingdom, 2016.

[9] Kumar, A., and Singh, G. "Effect of Nano Silica on Fresh, Hardened and Durability Properties of Cement Mortar: A Review", International Journal of Civil and Structural Engineering Research, Vol. 5, Number 2, 2018, pp: 81-85.

[10] Aly, S., Achraf, A., and Mohamed, Z. "Beneficial Use of Nano-Silica in Concrete: A Review", Trends in Civil Engineering and its Architecture, Vol. 1, Number 1, 2018, pp:1-3.

[11] Ayad, A., and Said, A. "Using Colloidal Nano Silica to Enhance the Performance of Cementitious Motars", Open Journal of Civil Engineering, Vol. 8, Number 1, 2018, pp: 8289.

[12] Kaura, J. M., Lawan, A., Abubakar, I., and Ibrahim, A. "Effect of Nanosilica on Mechanical and Microstructural Properties of Cement Mortar", Jordan Journal of Civil Engineering, Vol. 8, Number 2, 2014, pp: 180-186.

[13] Jayaseelan, R., Pandulu, G., and Selvan, S. "Investigation on the Performance Characteristics of Concrete Incorporating 
Nanoparticles", Jordan Journal of Civil Engineering, Vol. 13, Number 2, 2019, pp: 351360.

[14] Behzadian, R., and Shahrajabian, $H$. "Experimental Study of the Effect of Nano-Silica on the Mechanical Properties of Concrete/PET Composites", Korean Society of Civil Engineering (KSCE) Journal of Civil Engineering, Vol. 23, Number 4, 2019, pp: 3660-3668.

[15] Domone, P. "Part 3: Concrete. In Construction Materials: Their Nature and Behavior", Fourth Edition, eds, Damon, P., and Illston, J., Spon Press, Tylor and Francis, 2 Park Square, Milton Park, Abingdon, United Kingdom, pp: 83-205, 2010.

[16] Neville, A. M, and Brooks, J. J. "Concrete Technology", Second Edition. Pearson Education Limited, Prentice Hall, Edinburg Gate, Harlow, Essex, England, 2010.

[17] Jayaseelan, R., Pandulu, G., and Selvan, S. "Investigation on the Performance Characteristics of Concrete Incorporating Nanoparticles", Jordan Journal of Civil Engineering, Vol. 13, Number 2, 2019, pp: 351360.

[18] Li, Z. "Advanced Concrete Technology", John Wiley and Sons Inc., Hoboken, New Jersey, United State of America, 2011.

[19] ACI 211.2-98. Standard Practice for Selecting Proportions for Normal, Heavyweight and Mass Concrete, American Concrete Institute, Farmington Hills, Michigan, United States of America, 2004.

[20] ASTM C33/C33M. Standard Specifications for Concrete Aggregate, American Society for Testing and Materials Harbor Drive, West Conshocken, Pennsylvania, United States of America, 2018.

[21] BS EN 12620. Aggregates for Concrete. Incorporating Annex A1(2008), British Standards Institution, Her Majesty Stationery Office, London. United Kingdom, 2002.

[22] BS EN933. Tests for Geometric Properties of Aggregatess-Part 1: Determination of Particle Size Distribution - Sieving Method, British
Standards Institution, Her Majesty Stationery Office, London, United Kingdom, 2012.

[23] BS EN12350. Testing Fresh Concrete - Part 2: Slump Test, British Standards Institution, Her Majesty Stationery Office, London, United Kingdom, 2009.

[24] BS EN12390. Testing Hardened Concrete - Part 1: Shape, Dimensions and other Requirements for Specimens and Moulds, British Standards Institution, Her Majesty Stationery Office, London. United Kingdom, 2012.

[25] BS EN 12390. Testing Hardened Concrete - Part 2: Making and Curing Specimens for Strength Tests. British Standards Institution, Her Majesty Stationery Office, London, United Kingdom, 2009.

[26] BS EN 12390. Testing Hardened Concrete - Part 3: Compressive Strength of Test Specimens, British Standards Institution, Her Majesty Stationery Office, London, United Kingdom, 2009.

[27] BS EN 12390. Testing Hardened Concrete - Part 6: Tensile Splitting Strength of Test Specimens, British Standards Institution, Her Majesty Stationery Office, London, United Kingdom, 2009.

[28] EN 1992. Eurocode 2: Design of Reinforced Concrete Structures - Part 1-1: General Rules and Rules for Buildings, European Committee for Standardisation, Brussels, Belgium, 2004.

[29] BS EN1008. Mixing Water for Concrete Specification for Sampling, Testing and Assessing the Suitability of Water, Including Water Recovered from Processes in the Concrete Industry, as Mixing Water for Concrete, British Standards Institution, Her Majesty Stationery Office, London, United Kingdom, 2002.

[30] BS EN 206. Concrete-Specification, Performance, Production and Conformity, British Standards Institution, Her Majesty Stationery Office, London, United Kingdom, 2013.

[31] MS Excel. Microsoft Office Excel, Microsoft Corporation, One Microsoft Way Redmond, WA 98052-7329, United States of America, 2007. 